\title{
E-mentoring: Does it have a place in medicine?
}

\section{Griffiths, H Miller}

\section{Technology supported mentoring within medical settings can complement and extend face to face monitoring.}

M entoring for doctors is clearly an important issue and has been the focus of recent debate. ${ }^{1-3} \mathrm{We}$ would like to add our own thoughts in one of the more controversial arease-mentoring. Over the past decade there has been a substantial increase in work into e-learning support, such as e-moderating, ${ }^{4}$ and other mentoring and support systems such as online communities of practice. ${ }^{5}$ It is not the intention here to explore these literatures but to concentrate specifically on one area-e-mentoring.

E-mentoring has been defined by Bierema and Merriam" as "a computer mediated, mutually beneficial relationship between a mentor and a protégé which provides learning, advising, encouraging, promoting, and modeling, that is often boundaryless, egalitarian, and qualitatively different than face-toface mentoring" (page 212). This definition has two elements that distinguish it from traditional mentoring - the boundaryless configuration and the egalitarian quality of the exchange. Although there has been much work on the effectiveness of non-electronic mentoring, less is understood about the dynamics, context, or results of e-mentoring. ${ }^{6}$

Many educators and organisations (including the medical profession) remain suspect about the new and growing field of e-mentoring. However, research by Preece and her colleagues ${ }^{7}$ has shown how the internet can be used to express empathy, particularly in online patient support communities. Furthermore, Griffiths ${ }^{8}$ has argued that online relationships can be just as real and intense as those in the offline world, and there should be little surprise that psychologists and educators are beginning to establish online therapeutic relationships. The argument also holds for e-mentoring. The time has come to embrace the new technology and to carry out evaluative research into this potentially innovative form of mentoring within medical-and othersectors.
People in the medical profession have offered each other electronic support ever since the internet was formed and bulletin boards became popular forums. E-mail can be received and responded to either immediately (that is, in real time) or it can be stored and responded to at the convenience of the user (that is, asynchronous time). ${ }^{9}$ It is probable that the most popular form of e-mentoring in medical settings occurs by e-mail. Other e-mentors may use text based chat rooms that permit some sort of conversation in real time and provides almost immediate feedback (albeit by typing rather than talking to each other).

A common form of e-mentoring is when older students participate in electronic classrooms, in which they can communicate with each other and with various instructors by e-mail, computer conferences, and chatrooms. ${ }^{4}$ A faculty member or other educational professional takes the role of e-moderator, whose job is to make sure interactions progress smoothly. The title "e-moderator" used by those who write about this role shows that it is not entirely a mentoring role, but aspects of the role like acculturation, building confidence, and modelling effective behaviour overlap with conventional definitions of mentoring. E-mentoring can also be used in supporting career development for professionals within an organisation (such as medicine). It is probable that much of this work is either not publicly visible, or if visible, is not much publicly analysed or reported.

There are a number of very good reasons why the internet is an excellent medium for most forms of help. For instance, research has consistently shown that the internet has a disinhibiting effect on users and reduces social desirability. ${ }^{10}$ This may lead to increased levels of honesty and therefore higher validity in the case of self disclosure. However, there is research that shows there are subtle interactions between anonymity, honesty, and self disclosure on line..$^{11}$
Through examination of the literature, e-mentoring seems to be advantageous for a number of reasons. Furthermore, all the advantages of e-mentoring are equally applicable in medical settings:

- It provides flexibility in pace and scheduling as the communication is asynchronous. ${ }^{13} 14$ The asynchronous nature also facilitates reflection because of the time delay of the communication. ${ }^{15}$

- It transcends physical and geographical boundaries. As long as internet access is readily available, e-mentoring can flourish. ${ }^{16}$

- It can provide access to people who may have previously been unable to access or want face to face mentoring services. ${ }^{17-19}$

- It is more egalitarian and democratic, with mentees being more comfortable in their own homes or workplace environment. ${ }^{1420}$ At best it can construct a virtual continuum where all parties involved mediate questions, answers, and discussion. ${ }^{13}$ However, it should also be pointed out that there is little evidence that being on line necessarily removes or reduces hierarchies or status differentials. ${ }^{21}$

- It may help decrease feelings of intimidation or discomfort, or both, in new environments because symbols of status are often unidentified-that is, the equalisation of the mentoring process. ${ }^{17} 18$

- It offers easy access to supportive information and resource experts. ${ }^{19}$ Information is just a "link" away.

- It can choose to adopt a single communication method, or choose to use multiple, simultaneous methods (for example, e-mail, listservs, Usenet, newsgroups, threaded discussions, and/or chatrooms). ${ }^{19}$

- It is potentially scalable: programmes may be enlarged or multiplied with comparatively low cost.

It would seem that in some situations (including those in a medical context), e-mentoring can be helpful. Furthermore, e-mentoring supporters will argue that there are responsible, competent, ethical mentors forming effective helping relationships via the internet, and that these relationships develop the mentee. However, e-mentoring may not appropriate for everyone and those participating should at the very least be comfortable in expressing themselves through the written word. As with any new frontier, there are some issues to consider before trying it. E-mentoring also provides many challenges: 
- Participants must have access to the internet.

- Participants must have the basic skills to use the software, equipment, and the internet.

- E-mentoring programmes must have continuous interactions and reflective influences through the duration of the programme.

- E-mentoring programmes can vary because of differences in participation motivation, involvement, and personal characteristics.

- E-mentoring programmes may be difficult to maintain, because they require coordination and management (both technical and human), facilitation and planning, and implementation and evaluation.

- There have been few evaluation studies on whether e-mentoring is effective in any way.

- E-mentoring may compromise privacy and confidentiality.

- For the e-mentor there is the problem that e-mentoring can be more time consuming than face to face mentoring.

- There may be difficulty in establishing rapport with someone that the e-mentor has never seen.

- Because there is no face to face contact, e-mentoring leads to a loss of non-verbal communication cues such as particular body language, voice volume, and tone of voice.

The effectiveness of mentoring (for example, DuBois et $a^{22}$ ) suggests that positive effects result from establishing a relationship with a significant other, which in turn provides social support and leads to increased psychological or behavioural competence. Research shows that trust and building relationships during e-mentoring is associated with agreement between the parties about frequency of communication, appropriately frequent and full communication, social as well as task based communication, some level of self disclosure, ${ }^{16}$ and interactive rather than purely reactive communications. ${ }^{23} 24$

E-mentoring clearly provides many challenges. Price and $\mathrm{Chen}^{19}$ point out that e-mentoring programmes can vary because of differences in participation motivation, involvement, and personal characteristics, which may make it difficult to maintain continuous interactions and reflective influences through the duration of e-mentoring programmes. In addition, e-mentoring programmes may be difficult to maintain, because they require coordination and management (both technical and human), facilitation and planning, and implementation and evaluation.

We would argue that technology supported mentoring within medical settings complements and extends what is achieved by face to face monitoring. Electronic mentors can provide feedback on clinical and medical issues, personalised attention, career advice, and encouragement. $^{23}$ However, as Kealy and Mullen ${ }^{25}$ observe, it is unresolved as to whether in-person experience can ever be fully substituted by technology.

Finally, Kealy and Mullen ${ }^{26}$ make some very astute observations. Technology is constantly changing in ways that are sometimes surprising and unpredictable. They point out that when new technologies appear they often look to the past to define themselves (for example, the invention of the car being described as a "horseless carriage" reflecting the "technology" it was meant to replace). Kealy and Mullen ${ }^{26}$ assert than instead of viewing e-mentoring with regards to its predecessor (that is, face to face mentoring), perhaps it should be understood on the basis of its unique qualities. Maybe, e-mentoring and traditional mentoring should not be compared at all. Traditional mentoring is unlikely ever to be replaced. However, new technologies may provide a useful adjunct to the mentoring boundaries.

Postgrad Med J 2005;81:389-390.

doi: 10.1136/pgmj.2004.029702

\section{Authors' affiliations}

M Griffiths H Miller, Psychology Division, Nottingham Trent University, Nottingham, UK

Correspondence to: Professor M Griffiths, International Gaming Research Unit, Psychology Division, Department of Social Sciences, Nottingham Trent University, Burton Street, Nottingham NG1 4BU, UK; mark.griffiths@ntu.ac.uk

\section{REFERENCES}

1 MacDonald R. Mentoring for doctors. BMJ Career Focus 2004;328:179.

2 Harborow PC. Mentoring for doctors. BMJ Career Focus 2004;329:19.

3 Saunders DJ. Mentoring for doctors. BMJ Career Focus 2004;329:19.

4 Salmon G. E-moderating. London: Routledge Falmer, 2000
5 Notess M, Plaskoff J. Preliminary heuristics for the design and evaluation of online communities of practice systems. eLearn Magazine 2003. http:// www.elearnmag.org/subpage/ sub_page.cfm? section $=4 \&$ list_item $=8 \&$ page $=1$ (accessed 6 Nov 2004)

6 Bierema LL, Merriam SB. E-mentoring: using computer mediated communication to enhance the mentoring process. Innovative Higher Education 2002;26:21 1-27.

7 Preece J, Ghozati K. Observations and explorations of empathy online. In: Rice RR, Katz JE, eds. The internet and health communication: experience and expectations. Thousand Oaks: Sage, 2001:237-60.

8 Griffiths MD. Sex on the internet: observations and implications for sex addiction. Journal of Sex Research 2001;38:333-42.

9 Lago C. Computer therapeutics. Counselling 1996:287-9.

10 Joinson A. Causes and implications of disinhibited behavior on the internet. In: Gackenback JJ, ed. Psychology and the internet: intrapersonal, interpersonal, and transpersonal implications. New York: Academic Press, 1998:43-60.

11 McKenna KYA, Bargh JA. Coming out in the age of the internet: edentity 'de-marginalization' from virtual group participation. J Pers Soc Psychol 1998;75:681-94.

12 Bargh JA, McKenna KYA, Fitzsimons GJ. Can you see the real me? The activation and expression of the 'true self' on the Internet. Journal of Social Issues 2002;58:33-48.

13 Noe RA. An investigation of the determinants of successful assigned mentoring relationships. Personnel Psychology 1988;41:457-79.

14 Sinclair C. Mentoring online about mentoring: possibilities and practice. Mentoring and Tutoring 2003; 11:79-94.

15 Ravet S, Layte M. Technology-based training. Houston, TX: Gulf Publishing, 1997.

16 Bennet D, Hupert N, Tsikalas K, et al. Critical issues in the design and implementation of telementoring environments. Centre for Children and Technology, 1998. http://www2.edc.org/ $\mathrm{CCT} /$ publications_report_summary.asp? numPubld $=39$ (accessed 6 Nov 2004).

17 Harasim L, Starr RH, Teles L, et al. Learning networks. Cambridge, MA: MIT Press, 1998.

18 Palloff RM, Pratt K. Building learning communities in cyberspace. San Francisco, CA: Jossey-Bass, 1999.

19 Price MA, Chen HH. Promises and challenges: exploring a collaborative telementoring programme in a preservice teacher education programme. Mentoring and Tutoring 2003; 11:105-17.

20 Ellis K. A model class. Training 2000;37:50-7.

21 Spears R, Postmes T, Lea $M$, et al. When are net effects gross products? (Letter). Journal of Social Issues 2002;58:91.

22 DuBois DL, Neville HA, Parra GR, et al. Testing a new model of mentoring. In: Noam GG Rhodes JE, eds. A critical view of youth mentoring. San Francisco: Jossey-Bass, 2002:21-57.

23 Rafaeli S, Sudweeks F. Networked interactivity. Journal of Computer Mediated Communication. http://www.ascusc.org/jcmc/vol2/issue4/ rafaeli.sudweeks.html (accessed 6 Nov 2004).

24 Packard BW. Web-based mentoring: challenging traditional models to increase women's access. Mentoring and Tutoring 2003; 11:53-65.

25 Kealy WA, Mullen CA. Guest editors' introduction: at the nexus of mentoring and technology. Mentoring and Tutoring 2003;11:3-13.

26 Kealy WA, Mullen CA. Epilogue: unresolved questions about mentoring and technology. Mentoring and Tutoring 2003;1 1:119-20. 